\title{
Malaysia: country report on children's environmental health
}

\begin{abstract}
Children's environmental health $(\mathrm{CEH})$ has become a main agenda in the National Environmental Health Action Plan (NEHAP) 2019 in Malaysia. Children are affected by exposure to many environmental hazards because they are uniquely vulnerable due to their immature immune systems and organs. This country report aims to review the environmental threats to CEH in Malaysia. There are a few key issues that have been identified, including air pollution, pesticides in food and water pollution. However, air pollution has been recognized as one of the major concerns in $\mathrm{CEH}$, coming from both localized and transboundary sources. The localized sources include traffic-related air pollutants, industrial waste incinerators, land clearing and open burning. In addition, due to the tropical climate, children are exposed to fungal toxins, mycotoxins, endotoxins and allergens from classroom dust. Transboundary pollutants from neighboring countries result in recurring haze episodes in Malaysia, causing a negative impact on public health, especially in children. All in all, improving CEH in Malaysia requires all stakeholders and related agencies to recognize the issue as a problem, to develop a harmonized action plan and to work together to promote the protection of human health, specifically of children.
\end{abstract}

Keyword: Air pollution; Children's environmental health; Environmental health; Malaysia 